\title{
Strategy-as-Process in a Technology Venture: A Case Study of Pivots, Pauses, Partners, and Progress
}

\author{
Andrew G. Earle, Michael J. Merenda, and J. Matthew Davis
}

\author{
"We thought we were being 'disruptive'. Time will tell if ") \\ we were, in fact, just being stubborn.
}

Founder of the technology venture featured in this study

\begin{abstract}
Technology commercialization is an often nonlinear process that tends to pass through various "stages" or "phases" as a venture attempts to shepherd a technology from the laboratory to marketplace. Between these phases are "junctures" or "transitions" that present particular challenges for entrepreneurs as they often comprise fundamental changes to the venture instead of simply scaled versions of previous challenges. In this study, we use a participantobserver methodology to deeply explore how a technology venture in the renewable energy sector negotiated these transitions. Our findings highlight the development of a "repertoire" of tools entrepreneurs can use to help successfully negotiate these transitions.
\end{abstract}

\section{Introduction}

Technology entrepreneurship is defined as "an investment in a project that assembles and deploys specialized individuals and heterogeneous assets that are intricately related to advances in scientific and technological knowledge for the purpose of creating and capturing value for a firm" (Bailetti, 2012). Commercialization is "the process of acquiring ideas, augmenting them with complementary knowledge, developing and manufacturing saleable goods, and selling goods in a market" (Mitchell \& Singh, 1996). Both of these closely related concepts are critical to developing science-based solutions to seemingly intractable social problems and sustaining firm competitiveness in technology-driven industries (Katila, 2002; Prahalad, 2011).

Past technology entrepreneurship research revealed barriers to commercialization such as the "Valley of Death" in which a given technology fails to make it to market because many funding sources focus on scientific novelty (such as grants for basic scientific research) and do not support the type of translational research needed to make such a technology attractive to private investors (Auerswald \& Branscombe, 2003). Similarly, researchers have highlighted "chasms" like that between enthusiastic groups of early adopters and the mass market that ultimately determine a venture's success (Moore, 1999).
Beyond these well-established barriers, researchers have found other, often subtler, obstacles including the difficulty in effectively traversing the conflicting logics of scientific research and market-focused commercialization (Vohora et al., 2004). Furthermore, these barriers often require fundamentally different managerial approaches rather than representing scaled-up versions of the same problem. For example, Fisher and colleagues (2016) demonstrate how institutional pressures vary, leading to legitimacy challenges as technology-focused ventures make their way from the laboratory to the market. Despite all of these laudable research efforts, technology commercialization remains challenging, and empirical evidence shows that very few inventions navigate this perilous transition to become true innovations (Markman et al., 2008; Moser, 2005).

In this study, we build on this research, while also taking a different methodological approach to understanding the technology commercialization process. By taking studies outlining increasingly nuanced views of the stages and phases of technology commercialization as showing the "contours" (Rasmussen, 2011) of this process, we examine how technology entrepreneurs deploy various tools in the transition between these phases. In so doing, we respond to calls for entrepreneurship researchers to engage in process-centered, longitudinal, and market-oriented studies of emergence 


\section{Strategy-as-Process in a Technology Venture: A Case Study of Pivots, Pauses, Partners, and Progress Andrew G. Earle, Michael J. Merenda, and J. Matthew Davis}

under conditions of uncertainty (Davidsson, 2003). This approach both helps add a dimension of "how" to the "what" examined in these previous studies, and it provides more concrete guidance to those directly involved in the technology commercialization process.

Previous research has provided limited guidance on negotiating transition points between stages of the commercialization process (Neergard, 2003; Rasmussen, 2011) and these transitions are still not well understood more generally (Fisher et al., 2016). A result, we use a qualitative inductive methodological approach, featuring participant observation, in an effort to gain deeper insights into our research question: how do entrepreneurs navigate key transition points in the phases of the technology commercialization process? Our goal in this study is to contribute to opening the "black box" of these transition points to better understand the tools used in these efforts by technology ventures.

In service of this goal, we first offer a focused literature review on stage-based models of entrepreneurship with particular attention paid to the consequences for technology commercialization contexts. Second, we present our case analysis of a technology commercialization venture in the promising area of sensors and data analytics used in renewable energy systems. Our analysis of this case unveiled a repertoire of tools the venture used when navigating its technology commercialization path and associated critical transition points. This notion of a repertoire from which actors can select is well established in research on organizational culture (e.g., Swidler, 1986) and has more recently been adapted to the context of product innovation (e.g., Seidel \& O'Mahony, 2014).

While some of these "tools" we observed have received increasing attention in both popular and academic outlets - such as "pivoting" (Crilly, 2018; Reis, 2011) - others such as strategic pauses are less developed within the literature. Mintzberg and Waters (1982) highlight the importance of "periods of pause, following periods of sprinting" for organizations to "remain viable" more generally, but they do not apply this concept to technology commercialization or early-stage ventures. Furthermore, our methods allow us to take a more holistic view of these tools so instead of examining whether or not a given tool is effective on average across a large population of ventures; we are able, for example, to examine the nuanced relationship between pivoting and pausing in the context of this particular case.

\section{Previous Research}

One of the foundational observations in research on technology commercialization (and entrepreneurship more generally) is that it is inherently $a$ process rather than an event or trait (Davidsson, 2003). As such, researchers have endeavoured to better understand this process by focusing on its progression from scientific discovery to marketable product. In an extreme but instructive example, Rothaermel and Deeds (2004) studied the technology commercialization process in the pharmaceutical industry. Here, chemical compounds are screened through numerous "models" (ranging from simple organisms to mice to human subjects) to assess a compound's feasibility as a pharmaceutical. Of course, the highly regulated and broadly linear technology commercialization process in the pharmaceutical industry likely represents an extreme case; however, the overarching idea remains the same: scientific discoveries must be tested and refined to eventually become commercialized products.

In another example, Dewald and Fromhold-Eisebith (2015) examined the photovoltaic (PV) industry's formation from its birth in the 1950s to its maturation in the 2000s. The researchers studied this industry through the lens of technological innovation systems, specifically sustainability-oriented technology. Their empirical study demonstrated "an expedient combination" of "territorial innovation system" approaches (regional, national, supranational, and international spaces) and its connections with major process-oriented fields (R\&D, knowledge development, technology production, market formation, and policy). The authors postulate that technology innovation systems are rescaled in time and space through the dynamic convergence of the different process fields and a focus on the convergence of technology innovation systems and national institutional systems by aligning technology with strengths of the national innovation system (e.g., prevalence of a nation's leading industries, technologies, and expertise). Whether it takes place at the macro- (institutional and policy), mezzo- (industry), or micro- (firm) level of analysis, this area of research has shown that, in addition to experiencing a nonlinear technology commercialization process, nascent technology entrepreneurs face the dynamic interplay of markets (e.g., industry maturation, legacy effects, and fights over standards and practices), technology development and integration (e.g., symbiotic relationships), and psychological (reliance on heuristic and mental models) challenges. 


\section{Strategy-as-Process in a Technology Venture: A Case Study of Pivots, Pauses, Partners, and Progress Andrew G. Earle, Michael J. Merenda, and J. Matthew Davis}

In addition to outlining high-level patterns, the literature illustrates that entrepreneurial ventures pass through several phases and confront critical junctures in their development. The literature also reveals that the intricacies and challenges faced by entrepreneurial ventures are similar regardless of industry or firm size. At each phase, ventures face strategic, financial, managerial, and organizational challenges, as well as issues with resource limitations and transition challenges (Churchill \& Lewis, 1983; Eggers et al., 1994). More specific to the technology-based venture context, Vohora and colleagues (2003) found the commercialization processes for spinouts based on university-generated technologies are also non-linear, often skipping stages or regressing to an earlier stage. These and other researchers found that early decisions and mistakes in this process can lead to substantial opportunity costs, including longer time to market, lost revenue, and lack of external investment (Eisenhardt \& Martin, 2000; Galunic \& Eisenhardt, 2001; Teece et al., 1997).

More recently, researchers have examined punctuated paths of technology commercialization and have argued that this process is more than merely refining a technology or searching for market alignment. For example, Fisher and colleagues (2016) develop a model in which new ventures based on university-generated technologies must traverse multiple "legitimacy thresholds" in which institutional pressures on the new venture change dramatically, thereby providing evidence that scaling requires a more systematic change to a venture than just doing more of the same, but on a larger scale.

\section{Methods}

To examine our research question, we employ a casebased methodology (Yin, 1989) to gain deeper insight into the tools and tactics used by technology-oriented entrepreneurs as they negotiate transition points (Figure 1) in the development of their ventures. Yin (1981) argues that case-based approaches are wellsuited to "attempt to examine: (a) a contemporary phenomenon in its real-life context, especially when (b) the boundaries between phenomenon and context are not clearly evident." This description fits our case study as we are examining the early stages of a new venture's evolution and focusing on the processes inherent in entrepreneurial activities (Davidsson, 2003). Specifically, we examine what Rasmussen (2011) classifies as the "teleological" processes of entrepreneurship, which aim to describe how entrepreneurs "are able to drive the project forward in a purposeful, or teleological, way" related to strategic decision making (Poole \& Van de Ven, 2004), adaptive learning (March \& Olsen, 1976), and the practice of strategy (Jarzabkowski, 2004).

In addition to adopting this exploratory case-based method, we also benefit from having a participant observer on our author team. Observation, including by participants, is employed in several disciplines as a technique to collect personal perspectives and cultural data in qualitative research (Kawulich, 2005). This design allows us unique access to understanding the "hows" and the "whys" of this case and has appeared

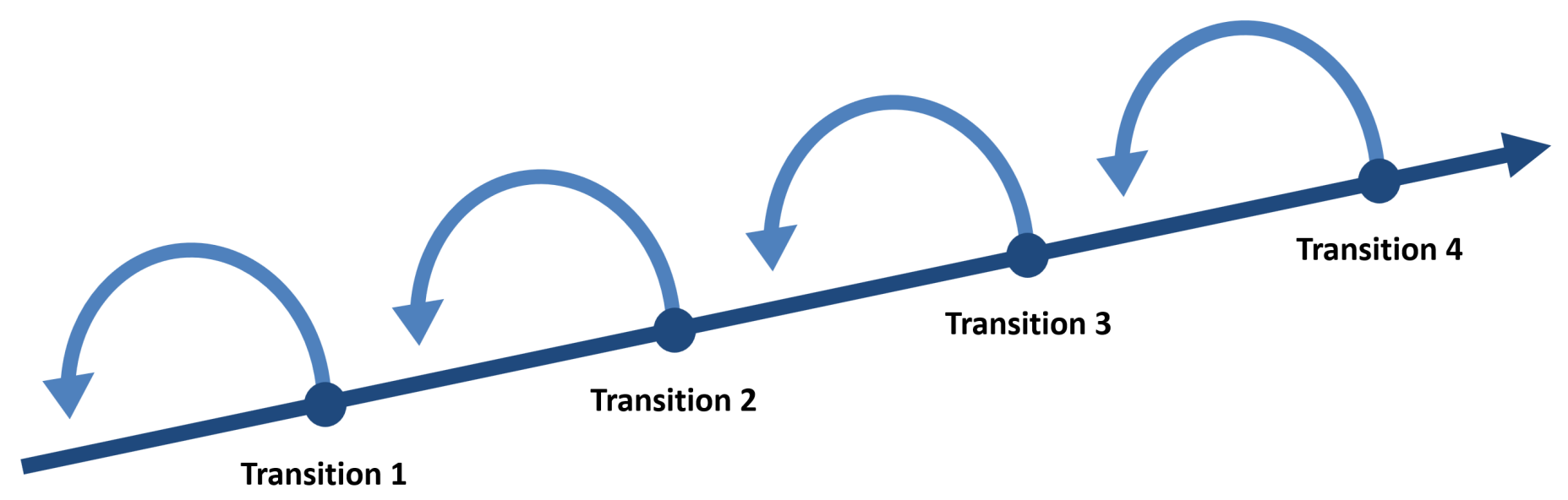

Figure 1. The recursive technology commercialization process with a focus on transitions 


\section{Strategy-as-Process in a Technology Venture: A Case Study of Pivots, Pauses, Partners, and Progress Andrew G. Earle, Michael J. Merenda, and J. Matthew Davis}

in related areas of research, such as examining the evolution of entrepreneurial networks (Jack et al., 2010). Furthermore, using a participant-observer approach for data collection helps answer calls for entrepreneurship research to more squarely focus on questions of emergence, as well as those of process (Davidsson, 2003).

\section{Case Selection and Setting}

We selected our case study based on access and its theoretical alignment with our research question. We believe our case excels at its alignment with our research question as it focuses on an early stage, but not a nascent, venture (having been founded in 2011). Therefore, it maps to early parts of stage-based models of technology entrepreneurship but also has existed long enough to offer a genuinely longitudinal perspective on the venture's evolution.

We also examined this venture "midstream" in its development (i.e., it is still an operating company). This timing allows us a unique vantage point in that we are not capturing prospective thoughts about what a potential founder might do, but a retrospective view on what a founder actually did in creating and managing their venture. As such, we are also not waiting for the ultimate outcome of the venture to study its evolution. As a result, such a midstream case selection helps avoid "survivorship" bias endemic in entrepreneurship research and contributes to "real-time" study of new venture processes (Carter et al., 1996).

The setting for our case is a technology venture called Energy Sensors LLC (a pseudonym). Energy Sensors' core product is a monitoring system (with hardware and software components) that can either be retrofitted to existing, or be integrated into new, geothermal heating and cooling systems. This technology allows system owners real-time analytics to assess the performance of their systems, replacing the guesswork and proxy measures that had been common industry practices. As such, Energy Sensors fits squarely with Bailetti's (2012) definition of technology entrepreneurship and other common definition of entrepreneurship more generally (e.g., Davidsson, 2003; Kirzner, 1983).

To help map Energy Sensors' journey to the phasebased frameworks described earlier, we asked our participant observer and Energy Sensors' founder to write an annotated timeline of critical events in his venture's formation and evolution. Once we had this more general timeline in place, we asked our participant observer to map the company's journey across the relevant phases to better illuminate how these transitions occurred. The timelines and additional conversations led to the development of an interview guide for collecting the founder's perceptions, observations, and experiences in starting and managing Energy Sensors. Based on this initial narrative, we then iterated through rounds of clarification, refinement, follow-on questions, and feedback from our participant observer. Given that we are particularly interested in the founder's navigation through the stages of his entrepreneurial journey, our questions and clarifications focused primarily on the critical junctures between phases.

\section{Case Study: Energy Sensors, LLC}

Energy Sensors was founded on the promise of widespread adoption of geothermal heat pump (GHP) technology as a critical element in reducing greenhouse gas emissions. Although changes in public policy to support renewable energy sources would be helpful, the founders believed market forces would ultimately drive large-scale adoption of GHP systems.

Energy Sensors' initial value proposition centered on the significant cost savings its technology could provide to GHP system operators and original equipment manufacturers (OEMs). For example, as a more efficient energy source, it was estimated that GHP technologies could deliver the same heating and cooling benefit for about half the cost of other heating and cooling methods. With this potential for energy savings in mind, Energy Sensors' initial value proposition mirrored that of the solar energy industry. Based on our participant-observer's annotated timeline of critical events in his venture's evolution, and his responses to the interview guide, we identified three phases and three sub-phases of this particular technology commercial process:

Phase 0 (2009-2010): R\&D, Idea, Discovery

Phase 1 (2011): Targeting, Customer Value Proposition Development

Phase 2 (2012-2016): Technology Application Phase 2a (Early 2012): Product Launch, Acquiring Resources, Trust Building

Phase 2b (Late 2012-2016): Re-Framing Technology and New Customers

Phase 2c (Late 2016): Fostering Collaborative Relationships

Phase 3 (2016): Quest for Profits 


\section{Strategy-as-Process in a Technology Venture: A Case Study of Pivots, Pauses, Partners, and Progress Andrew G. Earle, Michael J. Merenda, and J. Matthew Davis}

\begin{abstract}
Phase 0
Energy Sensors began based on our participant-observer's desire to apply his scientific work and interests in groundwater systems and data collection to solve similar problems related to heat flows associated with geothermal heat pumps (GHP). The founder's research interests coupled with his interests in serving the broader community as a scientist and researcher at a major research institution, and his financial motivation/job creation with a family business also acted as catalysts for phase 0. The founder launched Energy Sensors as a private entity separate from the university. He funded the startup and its initial intellectual property with his private funds and his co-founders' small equity investments.
\end{abstract}

The founder stated:

"There are many analogies in the status of GHP technology today and groundwater resource development. Both require a convergence of technology, motivated users/decision makers, and state and federal policies that enable market penetration (mainly in the form of infrastructure). While we see the necessary ingredients emerging for a GHP 'revolution', both the confidence in and awareness of the technology are lacking. Energy Sensors is working to develop technologies that will help overcome these barriers - specifically, cost-effective, and scalable monitoring and verification."

\section{Phase 1}

Phase I initiated Energy Sensors' investigation of commercialization opportunities for its GHP monitoring technology hardware and software. In 2011, the founder launched Energy Sensors, LLC. He wrote:

"Initial conception and product development (Spring/Summer 2011) included me and my wife as co-founders. Early on (Fall 2011), we brought on two engineers with some business and product development experience. Both had BS degrees in Mechanical Engineering and MBAs, and while in the MBA program, they started a small product development entity. They paid a nominal amount for approximately 10\% equity each. One had experience in the HVAC industry and ran a small business, while the other had experience in the development of electronics with connections in that field with some providers that we used in that space."

Critical to navigating this phase was an assessment of the technological viability of the initial hardware and software applications to determine if they could be commercially exploited; and, if so, how could they best create value? During this phase, Energy Sensors experienced technical and market uncertainties, capital constraints, and sometimes strained relationships with gatekeeping customers (e.g., GHP installers), all of which challenged Energy Sensors' ability to gain market traction and cash flow to cover rising start-up costs. To set the business on a path toward positive returns, the founders sought assistance through the local SCORE chapter and the state's Small Business Development Center (SBDC). The founder emphasized that a critical resource constraint was the limited time he could devote to the venture while maintaining his fulltime university position:
"It has been difficult to get others to really dig in- it is really hard to get something off the ground when you have a job and family. With a nine- month faculty appointment, I had one day a week for 'consulting', and nights, weekends, holidays, and summers for Energy Sensors, but that meant lost revenue to support family."

\section{Phase 2a}

In 2012, Energy Sensors released its initial product and began acquiring additional technical and professional expertise. This included a well-established GHP system design engineer with his own firm; a lead software developer; a marketing expert with a strong online presence in solar photovoltaic space; and a person with finance and project management skills who eventually became its part-time CEO. All hires were part-time and were incentivized through the adoption of a profit interest equity agreement. Still, the founder noted:

\section{"We had, and have, a pretty good team. With that said, they all have jobs, families, and other com- mitments, so getting what we need when we need it has been challenging."}

\section{Phase 2b}

Even with the added hires, Energy Sensors struggled to find the right technology applications for "paying" customers. This led to the founder's further investigation into the technical limitations of the company's software and monitoring system. During this phase, the founder noted that Energy Sensors experienced two major shifts in its trajectory. First, it moved from offering "customized" technology solutions to diverse customer needs to circling back to a more optimal set of standardized technology options. As company champion, the founder viewed the technology development 


\section{Strategy-as-Process in a Technology Venture: A Case Study of Pivots, Pauses, Partners, and Progress Andrew G. Earle, Michael J. Merenda, and J. Matthew Davis}

process as a learning opportunity, responding:

"We learned a lot through this real-time product development. I became the de facto GHP representative on the ASTM committee developing a heat meter standard for the U.S. The GHP industry would often call on me to work with State Energy Offices for consultation (mostly free). Collectively, this has established Energy Sensors as an objective expert in monitoring and verification (M\&V) of GHP systems."

The second trajectory change was repositioning the business by identifying and targeting a different set of paying customers and executing a "single customer development strategy". The founder explained:

"With limited resources, it is difficult to sustain a multi-front effort. Our initial target was the GHP system installer (residential, light commercial systems). We spent most of our effort on getting to installers. We joined the regional professional network and gave presentations at their annual meetings. Eventually, I ended up on the Board of Directors. While there was a great deal of mutual respect, they were not interested in our product/service and for reasons we now understand. We thought we were 'disruptive'. Time will tell if, in fact, we were just being stubborn. Our relationship with installers has been invaluable because we have earned their confidence and also learned A LOT [emphasis added by founder] about GHP technology and the industry."

\section{Phase 2c}

In this phase, the founder recognized the importance of Energy Sensors' involvement in regional sustainability efforts and GHP efforts that included many state agencies, suppliers, OEMs, practitioners, financial institutions, and other value chain players (mirroring past findings on the importance of national and regional institutions, and technology innovation systems). This collaborative participation and partnering proved critically important in the founder's success in both justifying and informing Energy Sensors' second round of R\&D through a United States Department of Energy (DOE) grant. The founder described his general approach in navigating transitions between phases $2 \mathrm{~b}$ to $2 \mathrm{c}$ :

"One big change is that, from Phase $2 b$ to $2 c$, we relied on a federal grant (DOE's Small Business Technology Transfer - STTR: Phase I). Co-founders committed to not go through additional fundraising sources or use personal funds. We reached the

\begin{abstract}
'break even' mark in 2014, and the rule was: no more debt. If an investor showed up at our door offering funds and expertise and willingness to lead, then we would reconsider, but we didn't want to be obligated to more people without having enough resources to really pull it off."
\end{abstract}

He continued:

\begin{abstract}
"Luckily, the DOE put out an SBIR/STTR topic that aligned with what we thought needed to be done and what we had established ourselves as being capable of doing; so we were successful in Phase I (SBIR/STTR: Phase I round). The Phase II application was not successful, but we were close to having a new product. We are exploring other opportunities to potentially get us to profitability."
\end{abstract}

What was evident in the founder's efforts to navigate critical junctures in the technology commercialization process was a great deal of change resulting from the continuous learning experienced by Energy Sensors' entrepreneurial team. This included interacting, partnering, and collaborating with customers, suppliers, investors, governmental agencies, and others in the sustainability and GHP industry clusters (i.e., the technological innovation system). Continuous learning and building trust enabled Energy Sensors to breakeven in 2014. This technology and business stabilization better positioned the company toward profits and value capture, with the founder observing: "most of 2016 we paused in pushing sales and began to work on building a market with larger stakeholders".

\section{Findings}

Figure 2 provides a conceptual model based on this case study. This model shows the contours of Energy Sensors' evolution and highlights the tools the company employed in its efforts to navigate critical junctures in the technology commercialization process. For simplicity, the linear path by which ventures move directly from one stage to the next was omitted (and was not something we observed in the case of Energy Sensors). As Energy Sensors approached the transition between phase 1 and phase 2, it had several alternative paths. It could pivot (represented by the broad-dash line) and enter a recursive part of the process, returning it to phase 1 (or earlier) in an effort to discover a more viable technology and market opportunity. This would have transitioned the founder back to continued $R \& D$, technology development, and idea formation. The founder observed: 


\section{Strategy-as-Process in a Technology Venture: A Case Study of Pivots, Pauses, Partners, and Progress Andrew G. Earle, Michael J. Merenda, and J. Matthew Davis}

"Let's use what we've learned, the relationships that we've built, and try to solve this problem again - back to the drawing board, but in a much better position than before. I don't think our initial trajectory/strategy was wrong and I don't think anyone could have known then what we know now, so it's not a sense of 'Shucks, we miscalculated, let's go in a different direction."”

A second technique used by the founder was to partner and problem solve with a previously uninvolved party (in this case, the university) in the DOE grant application process. This effort, as represented by the narrowdash line in Figure 2, resulted in receiving an SBIR/STTR Phase I DOE grant. The partnership and grant became the catalyst needed to navigate the transition from phase $2 \mathrm{~b}$ to $2 \mathrm{c}$.

A third technique (represented in Figure 2 by the circle at the end of the main venture path) utilizes a purposeful pause to reassess the challenge of transitioning to the upcoming phase. For conceptual clarity, these alternative paths are visualized in Figure 2 as separate techniques. However, these could also be used in concert as when the founder reported using a pause to enable a broader search for more capable partners:

"In late 2016, when we had come to the realization that our technology was not sufficient to meet the need that we had set out to address (cost-effective, scalable, GHP systems), we were going to shut it [Energy Sensors] down. When the SBIR/STTR topic was released in October 2016, it gave us one more shot to use what we had learned and see if we could pull it off. That was also an opportunity to formalize a university-Energy Sensors partnership."

Figure 2 suggests that transitions are more than merely a test of a venture "as is" where the more viable ones are filtered out from the less viable ones, or a proverbial locked "gate" that ventures slam up against and must rapidly pivot to find the right "key." Instead, transitions offer an occasion to pause, refit, reinforce, and refocus for subsequent stages of the technology commercialization process, which may look very different from previous ones.

"In fact, our redirection/reinvention has relied upon data that has been collected over the past several years - so there is no way that we could do what we are doing now without the initial 'failure."

Beyond the specific techniques used by Energy Sensors to engage with these transitions, Figure 2 suggests the utility of thinking beyond the "process" of technology commercialization to viewing it as a bundle of iterative and mutually interdependent "processes." The founder describes it as:

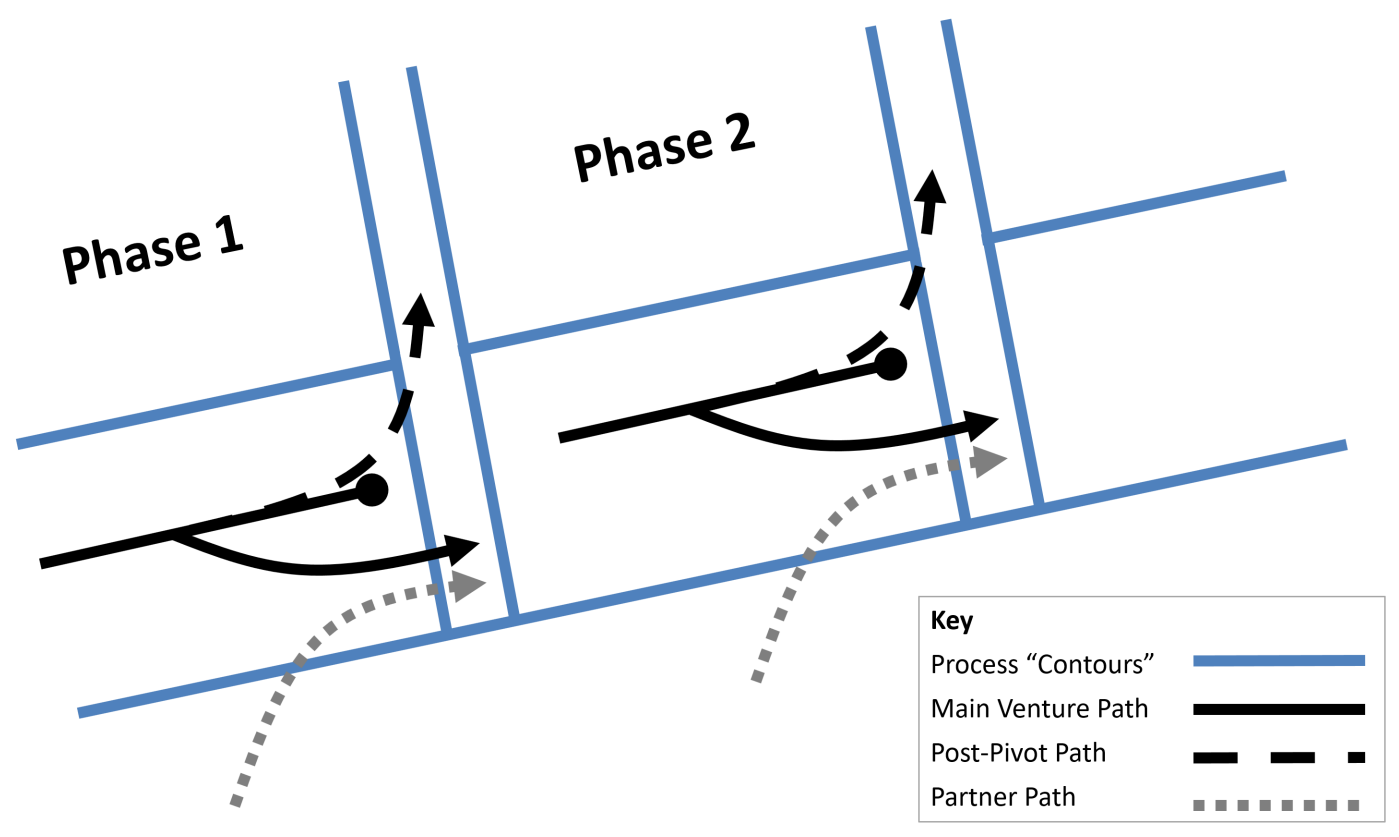

Figure 2. Transition repertoire model of how a company navigates critical junctures in the technology commercialization process 


\section{Strategy-as-Process in a Technology Venture: A Case Study of Pivots, Pauses, Partners, and Progress Andrew G. Earle, Michael J. Merenda, and J. Matthew Davis}

\begin{abstract}
"[A]n iterative process that remained focused on the end goal of increasing market penetration of renewable energy. The technology has been characterized as a necessary enabling technology, and there is an ongoing process of identifying what the needs of the market are and whether or not the technology can meet those needs."
\end{abstract}

\section{Discussion}

Our case study echoes previous findings by illustrating that navigating key transitions is more complicated than merely forging ahead linearly or quickly pivoting back through a given phase of development. Instead, we observed an entrepreneur working to build a repertoire of techniques to assist in managing these transitions. Within this repertoire, pivoting (as outlined in the lean startup methodology, [Reis, 2011]) is something increasingly common in technology-based ventures. However, pivoting was one of several approaches employed by Energy Sensors when navigating this technology commercialization process. For example, Energy Sensors transitioned from a retrofit-focused technology application (i.e., adding its solution to installed GHPs) to potentially partnering with utilities interested in the company's expertise in interpreting data. Thus, Energy Sensors had to pause and wait for these new customers to be ready to adopt their more advanced innovations.

This type of "strategic pause" mirrors recent attention on the importance of timing in entrepreneurial success as highlighted in popular outlets such as TED Talks (e.g., Bill Gross' 'The Single Biggest Reason Why Startups Succeed") and business-press books (e.g., Adam Grant's Originals). As with our findings regarding pivots, strategic pausing does not imply waiting for the sake of waiting; it is that intentional pausing and careful monitoring of how partners or customers are "catching up" that is a critical skill for technology entrepreneurs to have in their commercialization repertoires.

The third part of the repertoire featured in this case focuses on partnering. As with pivoting, technology entrepreneurs' need to find strategic partners is not new. However, our case highlights the need to not only partner in general, but also continually refine a venture's partnership capabilities given that such partnerships may not always follow a specific formula (Dewald \& Fromhold-Eisebith, 2015). The temporal and spatial dynamics found in the larger institutional systems (such as at the national level) and technology innovation systems reveals the usefulness of pausing and purposefully searching for particular partners in the technology commercialization process. For example, Energy Sensors first focused on investors and only later did it turn toward other partners such as standards-making bodies, universities, and key industry players (OEMs, suppliers, and utilities).

Given that we do not yet know the ultimate outcome of Energy Sensors as a venture, we are not advocating that other technology entrepreneurs necessarily follow this particular path. However, Energy Sensors does provide an example of a non-obvious partnering pattern while highlighting "why" effectively partnering with a range of actors found in a technology innovation system is an essential part of any venture's repertoire. As a venture approaches critical junctures, reframing its approach to partnerships may prove an essential tool for navigating these transitions. For example, Energy Sensors recast GHP installers from stuck-in-their-ways traditionalists in need of "disruption" to "invaluable" partners with whom the company needed to build trust and confidence.

\section{Future Research}

This exploratory study captures our participant-observer's experiences in navigating critical junctures over several phases in the technology commercialization process. Inherent to this methodological approach is a tradeoff between the depth of access to the entrepreneur's "behind the scenes" perspective on the earliest phases of their venture and more immediately generalizable findings. As such, we view this study as an earlystage effort in casting light on (especially the earliest) interstices in the technology commercialization process and its main contribution being a set of questions on transitional repertoires that we hope will be more fully elaborated, and eventually empirically tested, in future research.

As an immediate next step, a multiple case-study design (or triangulation within this particular case) could do more to suggest a generalizable model of the process we have observed here. For Energy Sensors, its process was influenced by the dynamic nature and interplay of external (e.g., institutional and industry technical, social, political, legal) and internal (e.g., technology development, market identification) factors that likely shape all such technology commercialization processes. However, whether the repertoire that Energy Sensors developed and deployed represents a common set of tools for entrepreneurs remains an open question. Building on this effort to add breadth to the depth offered in this 


\section{Strategy-as-Process in a Technology Venture: A Case Study of Pivots, Pauses, Partners, and Progress Andrew G. Earle, Michael J. Merenda, and J. Matthew Davis}

case study, a survey of technology entrepreneurs on their experiences with the early stages of the commercialization process would also help support the generalizability (or lack thereof) of our case-based findings.

Beyond these methods-based suggestions, future research could also consider not just what is available in an entrepreneur's repertoire (pivoting, pausing, and partnering, in the case of Energy Sensors) but under what circumstance each of these could be used, alone or in concert, to help ventures successfully navigate transitions and set them up for success in the next phases of their development. Such a study would require going beyond our largely exploratory and descriptive approach to testing the impact of variation in repertoire use on firm performance or other indicators of new venture success (e.g., user adoption, equity investment).

\section{Conclusions}

As with any case-based research, our goal was not to define or test the optimal technology commercialization process. Instead, we utilized a participant-observer methodology to gain deep insight "behind the scenes" on a portion of the technology commercialization process not often captured in past research. Specifically, we examined how a technology entrepreneur conceptualized, negotiated, and managed early-stage transition points in their technology commercialization process. Instead of testing a predefined model, we used this perspective to uncover new ideas and patterns that have the potential to both inform future quantitative research and provide practicing entrepreneurs with some options to consider as they face the same transitions as Energy Sensors.

Our findings indicate that developing a "repertoire" of techniques, including pivoting and pausing, before attempting to traverse key transition points is a useful (and actionable) practice for technology-focused entrepreneurs. Our research also suggests that entrepreneurs should develop and practice each technique in this repertoire so when the venture's development calls for its use, it will be reasonably well mastered before it is truly needed.
For the technology entrepreneur, becoming comfortable with pivoting or partnering aligns well with mastering routines that can contribute to the success of an organization. In contrast, practicing pausing may sound less intuitive. However, in a world with mantras like "move fast and break things" or "fail fast, fail often" which celebrates traits like "single-mindedness" and "obsession," an ability to execute a disciplined, focused, intentional, and strategic pause may be precisely the kind of thing many entrepreneurs need in their repertoires to help set them apart, spur further innovation, and take stock of their surroundings. In conclusion, we view this study as one modest contribution to provide a more operational perspective to both active and potential technology-focused entrepreneurs who need effective tools to navigate the currents, shoals, and reefs inherent in the technology commercialization process.

\section{About the Authors}

Andrew Earle is an Assistant Professor of Strategic Management and Entrepreneurship in the Paul College of Business and Economics at the University of New Hampshire in the United States. His research interests grow out of a long-held fascination with the transformational power of new technologies. The core of his research program is developing new ways of understanding how technologies move from initial invention to marketable products and how this process affects and informs the strategies of participating organizations.

Michael J. Merenda is a Professor of Strategic Management and Entrepreneurship in the Paul College of Business and Economics at the University of New Hampshire in the United States. His focus is on problem-solving, critical inquiry, and strategic thinking as it applies to strategic management and entrepreneurial education.

J. Matthew Davis is an Associate Professor of Earth Sciences at the University of New Hampshire in the United States. His research focuses on hydrology and water resources. 


\section{Strategy-as-Process in a Technology Venture: A Case Study of Pivots, Pauses, Partners, and Progress Andrew G. Earle, Michael J. Merenda, and J. Matthew Davis}

\section{References}

Auerswald, P. E., \& Branscomb, L. M. 2003. Valleys of Death and Darwinian Seas: Financing the Invention to Innovation Transition in the United States. The Journal of Technology Transfer, 28(3-4): 227-239. https://doi.org/10.1023/A:1024980525678

Bailetti, T. 2012. Technology Entrepreneurship: Overview, Definition, and Distinctive Aspects. Technology Innovation Management Review, 2(2): 5-12.

http://doi.org/10.22215/timreview/520

Carter, N. M., Gartner, W. B., \& Reynolds, P. D. 1996. Exploring StartUp Event Sequences. Journal of Business Venturing, 11(3): 151-166. https://doi.org/10.1016/0883-9026(95)00129-8

Churchill, N. C., \& Lewis, V. I. 1983. The Five Stages of Small Business Growth. Harvard Business Review, 61: 30-50.

Crilly, N. 2018. 'Fixation' and 'The Pivot': Balancing Persistence with Flexibility in Design and Entrepreneurship. International Journal of Design Creativity and Innovation, 6(1-2): 52-65. https://doi.org/10.1080/21650349.2017.1362359

Davidsson, P. 2003. The Domain of Entrepreneurship Research: Some Suggestions. In J. Katz \& D. Shepherd (Eds), Cognitive Approaches to Entrepreneurship Research: Advances in Entrepreneurship, Firm Emergence and Growth, Vol. 6: 315-372. Bingley, UK: Emerald Group Publishing Limited.

Dewald, U., \& Fromhold-Eisebith, M. 2015. Trajectories of Sustainability Transitions in Scale-Transcending Innovation Systems: The Case of Photovoltaics. Environmental Innovation and Societal Transitions, 17: 110-125.

https://doi.org/10.1016/j.eist.2014.12.004

Eisenhardt, K. M., \& Martin, J. A. 2000. Dynamic Capabilities: What Are They? Strategic Management Journal, 21(10-11): 1105-1121. https://doi.org/10.1002/10970266(200010/11)21:10/11<1105::AID-SMJ133>3.0.CO;2-E

Eggers, J. H., Leahy, K. T., \& Churchill, N. C. 1994. Stages of Small Business Growth Revisited: Insights into Growth Path and Leadership/Management Skills in Low- and High-Growth Companies. In W. D. Bygrave (Ed.), Frontiers of Entrepreneurship Research: 131-144. Babson Park, MA: Babson College.

Fisher, G., Kotha, S., \& Lahiri, A. 2016. Changing with the Times: An Integrated View of Identity, Legitimacy, and New Venture Life Cycles. Academy of Management Review, 41(3): 383-409. https://doi.org/10.5465/amr.2013.0496

Galunic, D. C., \& Eisenhardt, K. M. 2001. Architectural Innovation and Modular Corporate Forms. Academy of Management Journal, 44(6): 1229-1249.

https://doi.org/10.5465/3069398

Grant, A. 2017. Originals: How Non-Conformists Move the World. New York: Penguin.

Gross, B. 2015. The Single Biggest Reason Why Startups Succeed. TED, March 2015.

https://www.ted.com/talks/bill_gross_the_single_biggest_reason_ why_startups_succeed

Jack, S., Moult, S., Anderson, A. R., \& Dodd, S. 2010. An Entrepreneurial Network Evolving: Patterns of Change. International Small Business Journal, 28(4): 315-337. https://doi.org/10.1177/0266242610363525
Jarzabkowski, P. 2004. Strategy as Practice: Recursiveness, Adaptation, and Practices-in-Use. Organization Studies, 25(4): 529-560. https://doi.org/10.1177/0170840604040675

Kawulich, B. B. 2005. Participant Observation as a Data Collection Method. Qualitative Social Research, 6(2): 43. http://dx.doi.org/10.17169/fqs-6.2.466

Katila, R. 2002. New Product Search Over Time: Past Ideas in Their Prime? Academy of Management Journal, 45(5): 995-1010. https://doi.org/10.5465/3069326

Kirzner, I. M. 1983. Entrepreneurs and the Entrepreneurial Function: A Commentary. In J. Ronen (Ed.), Entrepreneurship. Lexington, MA: Lexington Books.

March J. G., \& Olsen, J. P. 1976. Ambiguity and Choice in Organizations. Bergen, Norway: Universitetsforlaget.

Markman, G., Siegel, D., \& Wright, M. 2008. Research and Technology Commercialization. Journal of Management Studies, 45(8): 1401-1423. https://doi.org/10.1111/j.1467-6486.2008.00803.x

Mintzberg, H., \& Waters, J. A. 1982. Tracking Strategy in an Entrepreneurial Firm. Academy of Management Journal, 25(3): 465-499. https://doi.org/10.1111/j.1741-6248.1990.00285.x

Mitchell, W., \& Singh, K. 1996. Survival of Businesses Using Collaborative Relationships to Commercialize Complex Goods. Strategic Management Journal, 17(3): 169-195. https://doi.org/10.1002/(SICI)1097-0266(199603)17:3<169::AIDSMJ801>3.0.CO;2-\#

Moore, G. A. 1991. Crossing the Chasm: Marketing and Selling HighTech Products to Mainstream Customers. New York, NY: Harper Business.

Moser, P. 2005. How Do Patent Laws Influence Innovation? Evidence from Nineteenth-Century World's Fairs. The American Economic Review, 95(4): 1214-1236. http://dx.doi.org/10.1257/0002828054825501

Neergaard, H. 2003. The Process of Entrepreneurship: A Managerial and Organizational Journey. In C. Steyaert \& D. Hjorth (Eds.), New Movements in Entrepreneurship: 160-176. Cheltenham, UK: Edward Elgar.

Poole, M. S., \& Van de Ven, A. H. 2004. Theories of Organizational Change and Innovation Processes. In A. H. Van de Ven \& M. S. Poole (Eds.), Handbook of Organizational Change and Innovation: 374-397. Oxford, UK: Oxford University Press.

Prahalad, C. K. 2012. Bottom of the Pyramid as a Source of Breakthrough Innovations. Journal of Product Innovation Management, 29(1): 6-12. https://doi.org/10.1111/j.1540-5885.2011.00874.x

Rasmussen, E. 2011. Understanding Academic Entrepreneurship: Exploring the Emergence of University Spin-Off Ventures Using Process Theories. International Small Business Journal, 29(5): 448-471.

https://doi.org/10.1177/0266242610385395

Ries, E. 2011. The Lean Startup: How Today's Entrepreneurs Use Continuous Innovation to Create Radically Successful Businesses. New York: Crown Books. 


\section{Strategy-as-Process in a Technology Venture: A Case Study of Pivots, Pauses, \\ Partners, and Progress Andrew G. Earle, Michael J. Merenda, and J. Matthew Davis}

Rothaermel, F. T., \& Deeds, D. L. 2004. Exploration and Exploitation Alliances in Biotechnology. Strategic Management Journal, 25(3): 201-221.

https://doi.org/10.1002/smj.376

Seidel, V. P., \& O’Mahony, S. 2014. Managing the Repertoire: Stories, Metaphors, Prototypes, and Concept Coherence in Product Innovation. Organization Science, 25(3): 691-712.

https://doi.org/10.1287/orsc.2013.0879

Swidler, A. 1986. Culture in Action: Symbols and Strategies. American Sociological Review, 51(2): 273-286.

https://doi.org/10.2307/2095521

Teece, D. J., Pisano, G., \& Shuen, A. 1997. Dynamic Capabilities and Strategic Management. Strategic Management Journal, 18(7): 509-533.

https://doi.org/10.1002/(SICI) 1097-0266(199708)18:7<509::AID-

SMJ882>3.0.CO;2-Z

Vohora, A., Wright, M., \& Lockett, A. 2004. Critical Junctures in the Development of University High-Tech Spinout Companies. Research Policy, 33(1): 147-175.

https://doi.org/10.1016/S0048-7333(03)00107-0

Yin, R. K. 1981. The Case Study Crisis: Some Answers. Administrative Science Quarterly, 26(1): 58-65.

https://doi.org/10.2307/2392599

Yin, R. K. 1989. Case Study Research: Design and Methods, Vol. 5. Newbury Park, CA: Sage.

Citation: Earle, A. G., Merenda, M. J., \& Davis, J. M. 2019.

Strategy-as-Process in a Technology Venture: A Case

(cc) BY

Study of Pivots, Pauses, Partners, and Progress

Technology Innovation Management Review, 9(1): 9-19.

http://doi.org/10.22215/timreview/1208

Keywords: innovation systems, technology

commercialization, process research, technology

entrepreneurship, managing critical junctures and

transitions 


\section{Academic Affiliations and Funding Acknowledgements}
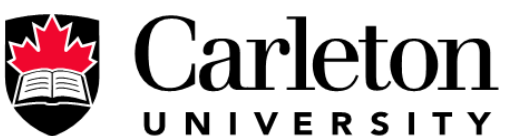

U N I V E R S I T Y

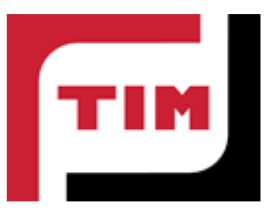

Technology Innovation Management (TIM; timprogram.ca) is an international master's level program at Carleton University in Ottawa, Canada. It leads to a Master of Applied Science (M.A.Sc.) degree, a Master of Engineering (M.Eng.) degree, or a Master of Entrepreneurship (M.Ent.) degree. The objective of this program is to train aspiring entrepreneurs on creating wealth at the early stages of company or opportunity lifecycles.

- The TIM Review is published in association with and receives partial funding from the TIM program. 